\title{
Culture of Self-education of the Teacher-Musician
}

\author{
E.A. Dyganova \& Z. M. Yavgildina \\ Kazan Federal University (the Volga region), Russian Federation, Kazan
}

\begin{abstract}
The article focuses on improving the professional performance of teachers of music, particularly, on achieving a higher level of the capability for self-education. Equipped by the techniques for self-education, a teacher-musician will continue to grow personally and professionally; the techniques determine the level of his/her professional achievements. The authors have developed, proved theoretically and implemented a set of schooling features in the academic practice of a teachers' training university. These aim at cultivating the culture of self-education, necessary for a teacher-musician for mastering the disciplines in the field of choir singing and conducting. The program has undergone a trial period of validation and the results give grounds to conclude that the authors' concepts are effective.
\end{abstract}

Keywords: self-education, self-education for music educators, the culture of self-education, a set of schooling features, disciplines in the field of conducting and choir singing, a future teacher-musician

\section{Introduction}

The recent social and economic transformations, the reforms in the system of professional education have led to changes in the domain of teachers' training, and in the domain of preparing teacher-musicians in particular. The target priority here is the preparation of teacher-musicians who would possess an integral set of competence: professional, specialized and generally cultural, and who would be capable of personal growth and professional self-education.

We regard the culture of self-education in a music coach as a phenomenon that exists between the system of interactions within the body of professional education and a teachermusician's personality. It presumes advanced scientific organization of the intellectual and creative activity, achieved through self-education in music and pedagogy. Self-education for music teachers is an independent, systematic, targeted cognitive activity involving the fields of pedagogy and music, and this is built on mature motivation and innate urges. The structure of the culture of self-education includes three interrelated components: that of values and motivation, of cognition and taking action, and that of control and reflection (Dyganova, 2014).

As a means of high formative potential we chose the area in the field of conducting and choir singing. The potential is here in the specifics of the initial stage in the training of a future teacher-musician in conducting and choir singing. It takes place apart from the "instrument of the choir", in the fact that the skills of this unit are tightly integrated, in the wide scope of in-class and out-of-the-class forms of training in choir singing and conducting; in the opportunity of 
multi-functional student activity; in the prevalent share of independent work of the students, which is favorable for gaining the experience in self-educating

Musical education has confronted an uneasy task of designing a systematic program for the student's self-educating activity, that would take into account the contemporary university environment, the specifics of training professional music educators, and the rich formative, enlightening and liberating potential of the arts of conducting and choir singing. The solution to the task appears to be in organizing the process of cultivating the culture of self-educating in a systematic way. As effective measures here that could bring positive changes into the training practice, we would regard the following set of schooling features:

- Structuring the content of the subjects of choir singing and conducting, in order to achieve the systematic character of a student musician's autonomous work;

- Mapping an individual path in developing the culture of self-education, building on the personal creative potential of a student;

- Organizing the teacher-student interaction in a dynamic way, while cultivating the culture of self-education, so that the teacher would become a role model and a moral authority;

- Implementing an "educational (pedagogical) technology" of cultivating the culture of selfeducation in a teacher-musician, in the process of mastering choir singing and conducting disciplines.

Our research is based on analyzing the scientific researches in education, dedicated to the numerous issues of self-education, of cultivating the capability for self-education in future musical educators, with regard to the specifics of teaching art, to the techniques of training a future teacher-musician in conducting. (Andreev, 2005; Abdullin \&Nikolaeva, 2004; Gunchenko, 2004; Gribkova, 2010; Zhivov, 2003; Kazatchkov, 1998; Slastenin, 2004, and others).

To specify the set of schooling features, necessary to achieve the goals mentioned above, we worked on studying the learning process in the higher institute of Arts of the Kazan Federal University, and on generalizing our personal experience of tutoring.

\section{The method}

As methodological ground for researches at a specifying scientific level we picked the personalityand-performance approach, the idea that culture and education are intertwined (Bondarevskaya, 2010; Valitskaya, 2005; Shcherbakova, 2001), the conceptual ideas about self-education and personal growth in the formative learning process (Abulkhanova-Slavskaya, 2001; Voronova,\&Melnikova, 2012; Karpova, 2009; Pidkasistiy, et al., 2010), all allowing to study the changes that take place in the process of cultivating the culture of self-educating in a music coach.

The following methods of research were employed to achieve the goal and solve the tasks:

\section{Theoretical methods:}

- analyzing references in psychology and education, the regulations, training programs and manuals on the professional training of a musical coach, scientific researches in the domain of modern training (education) technologies, and the methodological literature in the area of creating electronic educational resources; 
- comparing and generalizing the results of the theoretical research and thepractice of education;

- modeling the structure and the content of an educational technology.

Empirical methods:

- questionnaires, interviewing students and teachers on the problem of the research;

- the mentor' observations over the flow of the learning process;

- the comprehensive expertise of the results of the students' learning efforts and activity;

- an educational experiment;

- the mathematical processing and qualitative evaluation of the results obtained in the research.

\section{The Main Part}

For a teacher-musician, the culture of self-educating is an indicator of his/her competence, it is essential for his/her quick adaptation in the present day reality and for fast integration into the social and cultural context. Cultivating the culture of self-education in a teacher-musician, within the formative learning process, is a dialectic process, in which the following factors interact: the educational and additional information; the forms, methods and means of education and selfeducation; means of communication and their type; the personalities of the teacher and the student. It is proved by the science of pedagogy that the formative process will be effective in case of maintaining certain set of schooling features, which are to be designed depending on the objectives chosen.

In higher education, the term "a schooling feature" means a circumstance in the learning process that comes to be as a result of intentional selection, of constructing and applying the elements of the content, methods and organized forms of learning, in order to achieve specific educational purposes.

As practice shows, the positive result of the formative process is greatly determined by a complex realization of schooling features. Henceforth, if we aim at cultivating the culture of selfeducation in a teacher-musician as our major goal, we need to create such a set of schooling features, which could change the formative learning process in the way that would strengthen the motivation for self-education in a student, that would shape the readiness to autonomous learning and to gaining the experience of self-education activity.

In our opinion, the process of cultivating the capability for a teacher-musician's selfeducation will be the most efficient in the environment that would come as close to professional activity as possible. The use and the training potential of the unit of choir singing and conducting disciplines in cultivating the culture of self-education have been proved by the data from the comparative analysis of the diagrams showing the typical professional skills of a teacher of music and a choir conductor. (Dyganova \&Yavgildina, 2014) As a result of our work, we have designed such a set of schooling features:

\section{Structuring the content of the subjects from the unit of choir singing and conducting}

The choir-singing and conducting disciplines take the special place among the aspects of a future teacher-musician's preparation, which has to do with the specifics of mastering the profession, 
and the heavy labor input required on the part of the student as far as self-education is concerned. This self-education labor of the would-be teacher-musicians, in the process of mastering the choir-conducting, according to the academic programs, consists of: a) selecting the repertoire for exercising, according to the year of learning and the tasks and objectives of training; b) mastering the repertoire and studying the fragment from the lesson named "Working on a song", that has three sections: a conversation, a song demonstration, a choirmaster's work; c) selecting the repertoire for choirmaster practice with the student choir, taking into account the level of the performers' skill and the cast of the choir; d) the complex exercising of the vocal choir repertoire (the vocal, instrumental and manual aspects); e) selecting the repertoire and additional materials for creative, pedagogical, scientific competitions; f) writing summaries on the vocal choir pieces; g) creating arrangements for the choir; h) preparing scientific reports and articles; i) writing digests and course.

In order to systematically organize the autonomous work of the students in the choirconducting field, we took effort to structure the content of the subjects in choir singing and conducting and divided it into 5 basic "didactic building blocks", which correspond to the basic aspects of training in choir singing and conducting, i.e., the theoretical block is aimed at equipping the student musician with the theoretical knowledge in the domain of art and training in choir singing and conducting; the technical block aims at arming the student with an arsenal of techniques: the technique of conducting, the technology and psychological techniques of choir singing, the "pedagogical technologies" of working with choir teams; the research block has the objective of organizing and tutoring a student musician's work of scientific research; the performance block will equip the musician with the skills to perform vocal and choir plays as an artist in the choir or a choirmaster; the pedagogical block would coordinate the self-educating activity of the students in exercising the choral and vocal repertoire in a real professional environment, and also help them to analyze the scientific works on education, as well as the performance experience of recognized choir conductors.

In our opinion, such structuring of the choir-conducting field disciplines into "didactic building blocks" allows to reveal the "weak points" in the aspects of preparation in choir singing and conducting, and eliminate any gaps by means of properly organized self-educating activity of a student musician.

\section{Organizing the emergence of the self-education knack through formative path}

In the recent decade, there has been a steady trend to help the student move along his/her own formative path, or an individual educational path, which is mapped with regard to personal striving, individual educational and professional goals. An individual's educational path is a specifically designed educational program with selected objectives that would offer the student an opportunity to independently choose ways for its implementation. In this case, teaching means tutoring.

Traditionally, musical students used to be trained according to an individual educational plan, taking into account the unique personality of each student, but the responsibility for the level of professional preparation was entirely on the teacher. In our opinion, implementing an individual formative path for the students into the learning process would retain the wealth of achievements in music preparation practice, while adding into the learning process the independence and personal responsibility of the would-be teacher-musicians that we desire for their professional training. 
The individual formative path for a musical student employs the modular approach. Its structure includes the foundation module, that enforces the requirements of the State educational standards for the preparation of musical coaches, and the special (varied) modules of education extension, whose objective is to deepen or enlarge separate, individually and deliberately selected aspects of a teacher-musician's education, to take into account his/her personal creative potential.

In nurturing musicians, constructing the learning process with regard to individual needs is paramount, as every student musician is seen as a unique creative individual. The term "an individual" can be understood in a number of ways: the narrow meaning is that of an original creative personality, capable to generate new pieces of art; the general meaning is the unique set of qualities and abilities of each separate personality. In psychology, "an individual" is understood as a holistic set of distinct, unique attributes that manifest themselves in the specific temperament pattern, in the specifics of perceptive processes, in the structure and the extent of different abilities, in the features and qualities of the character. (Kirnarskaya, Kiyashchenko, \&Tarasova, 2003).

There are two mainstream concepts of managing an individual's talents in raising up musicians. The representatives of the first one tend to label the elements of a student's talent under the assumption that all students should be equally accomplished within a certain standard. The representatives of the second one use the well-known saying as a guiding tutoring principle that "one is only born as an individual, to become a personality", that is why the individual qualities of the student are used as effective gears to steer one's education. We should also keep in mind that using the strengths of the students' gift and potential has nothing to do with exploiting their capabilities in order to obtain flattering educational results.

V. I. Andreev, who is one of the researchers of the issue of the student's creative selfactualization, thinks that a university teacher should consider the following individual features of students in the formative process: the intellectual dimension, the dimension of needs and motivation, the emotional dimension, the domain of will, the specifics of self-control and selfbalance, the particulars of the existential aspect, and how the individual features of a student reveal themselves in object-oriented practice (Andreev, 2005).

In should be noted that the educational activity of a student musician has the style of a creative quest, so, when mapping an individual formative path, we also need to take into consideration the degree of accomplishment of separate musical abilities, the capability of improvisation, how well coordination is developed, the innate sensomotor performance abilities, the individual traits of character and temperament, the parameters of productivity (its speed, amount, quality), how wide the musical horizon is, whether the person possesses creative thinking, and how deep the student musician's professional self-awareness is (the self-awareness as a musical educator).

The realization of these features will give the opportunity to make the learning process more flexible and dynamic, focus on the conscious studying of the choir singing and conducting subjects in the context of the future professional activity, and help to define the vectors in selfeducating, which will further become an important part in cultivation of the culture of selfeducation in a future teacher-musician.

\section{Organizing the interaction between students and teachers in a dynamic way}

A motivated student will pursue the goal through his/her own path, the latter being determined by his/her character and talent. The teacher overcomes this path along with him/her, observing it, examining it, and tactfully directing the student - or, sometimes, even actively interfering with 
the course of events. The professional training of a teacher-musician is an challenging educational process, oriented towards 1) disclosing, detecting and developing the best of the student's abilities; 2) transferring the teacher's attitude to the student, regarding art and the profession, the teacher's knowledge, skills and techniques in performance and research. Undoubtedly, the teacher's mission is in the integral combination of these two aspects.

While cultivating the capability for self-education in a future teacher-musician, the teacher affects the student in a number of ways, using proper styles of mentoring interaction. We regard targeted and individual nurturing as the most effective; it builds up constant creative interaction between the teacher and the student. The teacher regards the student as an equal party in the interaction, as a junior colleague in joint exploration. The teacher encourages the student to make decisions, using the forms of active learning - which puts the student in the position of a "discoverer" of the truths, conscious intellectual and emotional efforts are demanded from the student, his/her opinion is taken into consideration, the independence of thinking is encouraged. The student musician is, then, actively absorbing and assimilating professional information,while relating it to his/her experience and personal qualities, and constantly improves his/her skill of self-education.

Nurturing the future teacher-musicians at university means, for the teacher, participating in all the main formative activities of the student, such as: musical performance, supportive educational organizing, analytical research, and in that of self-educating. Judging from the literature on psychology and education, and from our personal experience, we suppose that the teacher, as a role model, is the most important part in developing the capability for self-education in the student musician. Let us outline "the mentor's repertoire", which consists of 5 basic roles, that the teacher should be able to play, to really become a role model and a standard of professionalism for the student:

1. the mentor musician as the subject in the process of passing on the knowledge in music and teaching, of shaping professional competences and organizing the process;

2. the mentor musician as an explorer of music, as an author of scientific and scientificmethodological materials, as a participant of scientific conferences, symposiums, seminars, contests, and the supervisor of the scientific research of students;

3. the mentor as an organizer of practice for student-musicians;

4. the mentor as the participant in the systematic, targeted activity of a body of musical professors and tutors, as a subject of collective interaction, oriented towards one and the same result in united efforts;

5. the mentor as a subject in globalization and international interaction, a participant in international cooperation in science and education.

Regarding the emergence of the culture of self-education as a dynamic, phased process of student-teacher interaction, in it, we highlight three stages. At the first, initial stage, the teacher has the status of a maestro; he/she demonstrates the entire creative process of exploration, that is: identifying the problem, compiling a plan and then carrying it out step-by-step by means of creative problem-solving process, drawing the conclusions and implementing the results. The student has the position of an apprentice, who observes the teacher's actions and exercises according to an offered pattern.

The second stage is- cooperation. The mentor is responsible for the event-planning and control over the independent activity of the student in solving a chosen problem (planning, partly 
organizing and correcting). The student acts partly on his/her own, in order to solve the problem (there is joint planning, creative problem-solving, drawing conclusions).

At the third stage the student musician becomes the main party, he/she detects and defines the challenge, outlines the plan and the stages of its implementation, checks out for the possible solutions, articulates conclusions and puts the results into practice. This status is seen as interaction between colleague educators, the mentor's role being that of a consultant.

In our opinion, organized forms of dynamic interaction between teachers and students will give the opportunity to reveal such facets of personal and professional connection between the teacher and the student. It will allow a future music educator to obtain, in a consistent way, the culture of self-education.

The forth feature is - designing the "pedagogical technology" of obtaining the culture of selfeducation in future teacher-musicians, in the process of mastering the subjects in the fields of choir singing and conducting. In our research, we understand a pedagogical technology as a flexible functional system of all of the components of the nurturing process, which has a scientific foundation, unfolding in time and space into a program and leading to the targeted results (Selevko, 2005).

The main objective of the technology is developing the capability for self-education in future musical educators through mastering in the fields of choir singing and conducting. The ready pedagogical technology of obtaining the capability will include the following functional components of structure: mission, methodology, the content of the processes, and that of diagnostic revision and summary.

The cultivating process builds on the acknowledged methodological and tutoring approaches to education: systematic, holistic, knowledge-oriented, culturological and competence-oriented. As the leading principles by which to realize the technology, we would highlight the following ones: of consistency, of scientific approach, of the orientation of the learning process towards the holistic and harmonious progress of the student's personality, of the student's independence and ability to take deliberate action.

As for the aspect of the content of the processes, it is a more complex structure consisting of building blocks of the content, the methods, the forms of organized learning (traditional and additional), the means of learning (traditional and special). The content is represented by a wide range of materials on the subjects in choir singing and conducting, that the student is to master. Among the methods, we would highlight the following as the most effective: the methods of stimulating, motivating and self-motivating in learning; the methods of control and self-rating -of the efficiency of the learning and discovery process.

Examining the organized forms of learning, we must note that their range is very wide: as the forms of classwork - lectures, practice classes, seminars, practicums, individual classes as well as tasks for the autonomous work of students in class; outside classes, there is work for students to do on their own, such as preparing reports and participating in scientific conferences, preparing publications in science digests and magazines, taking part in specialized contests, thematic concerts, educational public lectures on music and in festivals, and the systematic visiting of concerts, theater plays, museums, displays, lecture-halls, master-classes, etc.

In the process of realization of the technology, we use the traditional means in the music tutoring - such as textbooks, printed music and manuals, visual means of teaching and equipment for demonstrations, technical aids to teaching. Our task required the development of 
special methodology materials, in the form of printed and electronic methodology textbooks written by the authors, a course for distance learning in the subject of "The History and the theory of choir singing" in the system of education management MOODLE.

The diagnostic component of revision and summary serves for validating the effect of the technology, while using the formative potential of the choir-conducting field disciplines. It consists of the structural components of the self-education capability that serve as the criteria indicating that the knack has been achieved (the component of values and motivation, the cognitive-operational one, and that of control and reflection), and the indicators that reflect their observable and measurable features, and the three levels (low, medium and high) at which the culture of self-educating can be acquired.

\section{Discussion and results}

The implementation of the set of formative schooling features in the academic practice of a university and the experimental work on obtaining the knack for self-education in future music coaches was conducted by the authors in the years of 2008-2014. As an experimental base the Higher School of Arts named after Salikh Saydasheff in the Kazan Federal University was used. The materials of our research underwent validity test in the Kazan State University of Arts and Culture, in the Chuvash Institute of Arts and culture. All in all, 384 students were involved in the experiment - all of them would-be teacher-musicians.

The experimental research had the following program:

1) Designing a system of criteria for assessing the levels at which the capability for selfeducating has been obtained;

2) Conducting the entry experiment that would test the initial level at which the selfeducating capability of the students;

3) Organizing the formative experiment, aimed at achieving a higher level of capability;

4) Conducting the control experiment that would check the final result and the level which the culture of self-educating has been formed.

Based on the structural components of the culture of self-educating of a future music coach that serve as the criteria of its accomplishment, we distinguished three levels and designed the indicators.

The low level: No interest in educating oneself, no understanding of the connection between self-education and personal and professional interests; the student possesses only the isolated elements of the basic knowledge in choir singing and conducting; s/he has no skills in selfeducation; the abilities of self-rating and personal and professional reflection are weak; there is insufficient mastery over the mechanisms of self-control and self-balance when educating oneself.

The medium level: There is an unsteady interest in educating oneself, the student has the understanding that self-education is connected with personal and professional interests; the student uses the basic knowledge in choir singing and conducting and is able to draw crosssubject links; s/he has difficulty in applying the knack for self-education and is partly capable of professional reflection and self-rating; occasionally s/he employs the mechanisms of self-control and self-balance in educating oneself. 
The high level: The student has clear understanding of the connection between selfeducation and personal and professional interests and is highly motivated to personal progress. The student possesses multi-aspect knowledge in choir singing and conducting and is wholly enriched by conscious cross-subject links. S/he has no problems applying the knack for selfeducation and has the abilities of self-rating and personal and professional reflection, and the mastery over the mechanisms of self-control and self-balance in educating himself/herself.

At the stage of entry test experiment 384 students were tested by means of the following methods: tutoring observation over the results, the students' independent work, interviews with students and teachers, offering questionnaires to the students in order to reveal the three levels at which the culture of self-educating currently is. The results of the "test dissection" are shown in Table 1.

Table 1

The levels at which the culture of self-educating in teacher-musicians is at the stage of the entry test

\begin{tabular}{|c|c|c|}
\hline \multirow{2}{*}{$\begin{array}{c}\text { The levels } \\
\text { of the culture of } \\
\text { self-educating }\end{array}$} & \multicolumn{2}{|c|}{ In total: $\mathbf{3 8 4}$ individuals (100\%) } \\
\cline { 2 - 3 } & The number of people & \% \\
\hline Low & 302 & 78.6 \\
\hline Medium & 58 & 15.1 \\
\hline High & 24 & 6.3 \\
\hline
\end{tabular}

The results of the entry stage of the education experiment gave grounds to draw the conclusion that the low level of culture of self-education is prevalent among the students, which confirms the relevance of the task of designing a set of schooling features that would improve the capability for self-education.

At the formative stage of the experiment we formed a group of control (GC) and an experimental group (EG). The students of EG (46 students) and GC (45 students) shared equal initial education environment, with the following features: the academic workload programs, formative academic programs, plans for student scientific activity, a working schedule that included class work and the academic workload outside classes, and others.

In order to examine the levels of improvement of the culture of self-educating in the future teacher-musicians at the formative and the control stages of the experiment, a complex of diagnostic methods was applied, aimed at verifying the levels of accomplishment for each component of the culture of self-education in a future musical educator. Table 2 shows the results of the initial stage of the formative experiment in the EG and the GC, that give grounds to state that abilities were fairly evenly distributed between the EG and the GC.

\section{Table2}

The data on the initial levels of accomplishment of the culture of self-education in the future teacher-musicians

\begin{tabular}{|c|c|c|c|c|}
\hline \multirow{2}{*}{$\begin{array}{c}\text { The } \\
\text { levels of } \\
\text { the } \\
\text { culture }\end{array}$} & \multicolumn{2}{|c|}{$\begin{array}{l}\text { The experimental group } \\
(46 \text { ind-ls, 100 \%) }\end{array}$} & \multicolumn{2}{|c|}{$\begin{array}{l}\text { The group of control } \\
(45 \text { ind-ls, } 100 \%)\end{array}$} \\
\hline & $\begin{array}{c}\text { The number of } \\
\text { people }\end{array}$ & $\%$ & $\begin{array}{c}\text { The number of } \\
\text { people }\end{array}$ & $\%$ \\
\hline Low & 30 & 65.2 & 27 & 60 \\
\hline
\end{tabular}




\begin{tabular}{|l|c|c|c|c|}
\hline Medium & 12 & 26 & 13 & 28.9 \\
\hline High & 4 & 8.8 & 5 & 11.1 \\
\hline
\end{tabular}

The educational purpose of the formative stage of the experiment was making the initial level of the capability for self-educating higher, through implementing a set of specific schooling features. The achievement of this purpose depended on solving the following tasks: 1) instilling into the students the distinct idea of personal and professional importance of self-educating in music and teaching, of personal and professional growth; 2) stimulating the self-education activity of the students in every aspect of training in choir singing and conducting; 3 ) nurturing the readiness to deliberately educate oneself in music and pedagogy; 4) organizing the environment for the students' self-development and fulfilling their musical destinies. It was expected that as a result of the formative experiment, the students of the EG will acquire the experience of selfeducating activity, its gaining being crucial for improving the culture of self-education in student musicians.

At the control stage of the experiment we again measured the achieved levels of culture of self-education necessary for a teacher-musicians with the students of the EG and the GC, using the same diagnostic inventory (see Table 3).

Table 3

The data on the levels of accomplishment of the culture of self-education in the future teacher-musicians at the control stage of the experiment

\begin{tabular}{|l|c|c|c|c|}
\hline \multirow{2}{*}{$\begin{array}{c}\text { The levels of the } \\
\text { culture of SE }\end{array}$} & \multicolumn{2}{|c|}{$\begin{array}{c}\text { The experimental group } \\
\text { (46 ind-ls, 100 \%) }\end{array}$} & \multicolumn{2}{c|}{$\begin{array}{c}\text { The group of control } \\
\text { (45 ind-ls, 10o \%) }\end{array}$} \\
\cline { 2 - 5 } & $\begin{array}{c}\text { The number of } \\
\text { people }\end{array}$ & $\%$ & $\begin{array}{c}\text { The number of } \\
\text { people }\end{array}$ & $\%$ \\
\hline Low & 13 & 28.3 & $\mathbf{2 2}$ & 48.9 \\
\hline Medium & $\mathbf{2 2}$ & 47.8 & 16 & 35.6 \\
\hline High & 11 & 23.9 & 7 & 15.5 \\
\hline
\end{tabular}

The summarizing diagram (Figure 1) allows to compare visually the initial and final results regarding the levels of accomplishment of the culture of self-education among the students of the EG and the CG, and observe the dynamics.

The summarizing diagram that demonstrates the initial and final levels of accomplishment of the culture of self-education in teacher-musicians is provided in the next page.

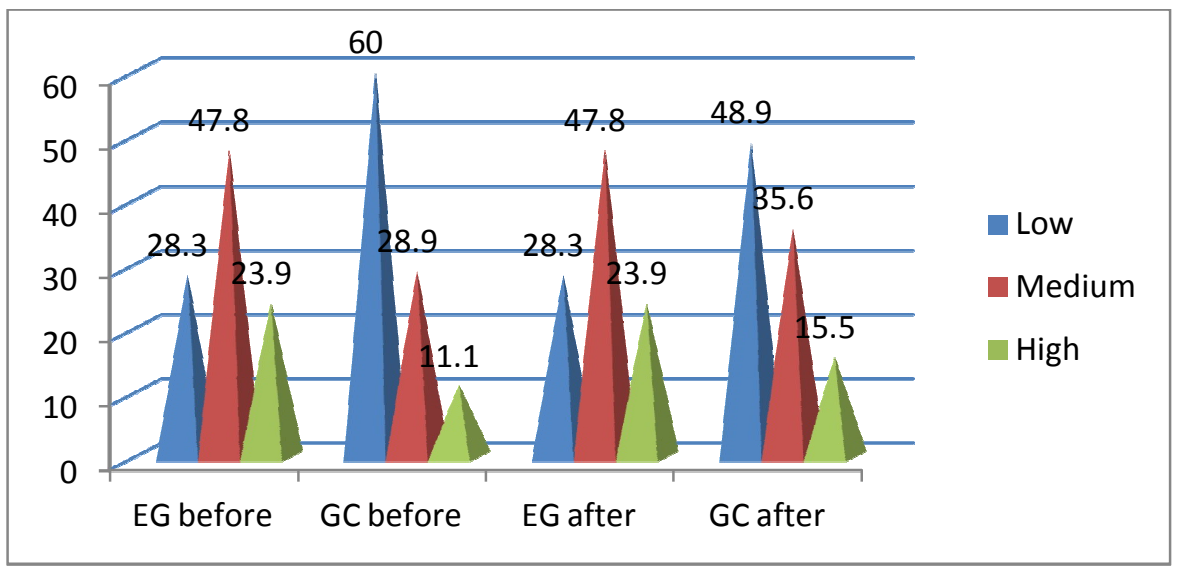

Fig. 1 


\section{Conclusions}

We can see that the data obtained at each stage of the experimental work on implementing a specifically designed set of schooling features in the learning process at university reflects a positive trend with the students of the experimental group, towards the growth of the level of the required culture of self-education.

1. The culture of self-education has proved to be an important factor that allows the teachermusician to continually develop his/her individual potential, to enlarge the scope of their professional activity and to raise the level of their professional ethics.

2. We have specified and scientifically justified the set of schooling features that would be favorable for shaping of the self-educating capability in a teacher-musician systematically, while mastering the subjects in choir singing and conducting, and that are aimed at unfolding the professional potential of an individual, at focusing him/her on using and knowing their strengths in further professional activity.

3. A series of education experiments has been conducted, that allowed to gather generalized data on the implementation of a set of specific schooling features in practice at the university level, in order to help obtaining in future teacher-musicians the culture of self-education.

4. The offered tutoring scheme for developing the culture of self-education has proved to be efficient, it allows to optimize the future musical coach's preparation, in the course of mastering the subjects in choir singing and conducting, and to achieve a higher level of the culture of self-educating in teacher-musicians.

\section{Acknowledgements}

The research was conducted by means of the financing granted within the program of state support of the Kazan (the Volga area) Federal University, in order to increase its competitive strength among the leading world centers of science and education.

\section{References:}

Abdullin, E.,\&Nikolaeva, E. (2004).The theory of music education: a textbook for higher education teachers' training institutions. Moscow: Academia Publishing.

Abdulkhanova, K.,\& Berezina, T. (2001).The time of personality and the time of life. SaintPetersburg:Aleteya.

Andreev, V. (2005).Tutoring at university. An innovative prognostic course: a manual. Kazan: The center of innovative technologies.

Bondarevskaya, A. (2010). The culture and education continuum of a university as an environment for the students' personal and professional accomplishment. Rostov-on-Don:Bulat.

Valitskaya, A. (2005).The new Russian school: the model of culture-generating. Saint Petersburg: The publishing house of the RSTTU named after A. I. Gertzen.

Voronova, T., \&Melnikova, E. (2012).Developing an information educational environment in a contemporary school. From a model to practical implementation. Lambert Academic Publishing, Germany.

Gunchenko, I. (2004). The personal progress of teachers within the system of continual professional selfeducation. PhD thesis, The Krasnodar Academy of the Russian Home Office, Krasnodar, Russia.

Gribkova, O. (2010). The theory and practice of shaping the professional ethics of a music educator. PhD thesis, The Moscow city teachers' training university, Moscow, Russia. 
Dyganova, E. (2014), Cultivating the culture of self-education in a future music educator in the process of mastering the disciplines in the field of choir singing and conducting. PhDthesis, Kazan (the Volga region) Federal University, Kazan, Russia.

Dyganova, E.,\&Yavgildina, Z. (2014).Cultivating the culture of self-education in a future teacher-musician: $a$ monography. Kazan:IFMK KFU.

Zhivov, V. (2003).Choir singing: theory, methodology, practice. A manual for the students of higher education institutions. Moscow:The humanities publishing center VLADOS.

Kazatchkov, S. (1998).The conductor of a choir as an artist and an educator. Kazan: The Kazan State conservatoire.

Karpova, O. (2009). The tutoring concept of promoting the development of self-educating activity of university students. PhD thesis, The Urals State University of Sports, Chelyabinsk, Russia.

Pidkasistiy, P., Belyaev, V., Yuzefavichus, T., \&Mizherikov, V. (2010).Pedagogy. Moscow: Academia Publishing.

Kirnarskaya, D., Kiyashchenko, N., Tarasova, K., et al. (2003).The psychology of musical performance: theory and practice. A manual for the students of musical departments of higher education institutions, edited by G. M. Tcypin. Moscow: Academia Publishing.

Selevko, G. (2005).Pedagogical technologies building on didactic and methodological improvement of the UVP. Moscow:The SRI of school technologies.

Slastenin, V.,Isaev, I., \&Shiyanov, E.(2004). Pedagogy: a manual for higher education institutions. In V. A. Slastenin (Ed.), the 3rd stereotype edition. Moscow: Academia Publishing.

Shcherbakova, A. (2011).Music and man in creating the continuum of culture: a monograph. Moscow:RGSU. 